\title{
Curriculum Philosophy for Diverse Population
}

\author{
Bindu Ranaut \\ General Education Instructor \\ West Coast University Miami \\ Florida
}

\begin{abstract}
Globalization and diversity needs to be addressed not only in work place, but also in education. The students should know how to deal with Global audiences. Therefore, the instruction should be designed in a way which could bring students belonging to diverse background together to learn the skills not only required inside the class, but can be implemented in outside world too. The students should be taught the skills which are not only theoretical but also practical in real life scenarios. Since the beginning of the twentieth century the educators have been debating over and over again about what should be the main purpose of education. Some argue that the main purpose of education should not be the primacy of intellectual knowledge, as they believe not all the students will be able to succeed the intellectual program of study (Noddings, 2015).The intellectual knowledge holds an important place in learning and is worthwhile in itself, but when the students are taught the practical things about life their knowledge is valued for its practical use. John Dewey in his theory pointed out that we cannot rightly apply the label intellectual knowledge to a school course simply because it is called algebra or British literature. Courses in mathematics may be intellectually impoverished; courses in mechanics may be intellectually rich. It all depends on how these courses call upon the intellect in the acquisition and application of knowledge.
\end{abstract}

\section{Purpose of Education}

There is a need to teach the practical things because there is a vital interaction between acquisition and application of knowledge. Adler (1982) stated that "There are no unteachable children. There are only schools and teachers and parents who fail to teach them" (p.8). This claim about the children being teachable does not mean that all children will learn and apply the same amount of knowledge that is taught to them. It is to make all of them intellectually rich and to provide the guidance students need to make wise choices among them. To be faithful to the democratic ideal of the comprehensive school, students should be allowed to choose their track; they should not be assigned to one. Recently a new debate has been arising according to which it is stated that too many students are badly prepared for college and that the quality of our academic courses has fallen badly (Arum \& Roksa,2014). We may have succeeded in getting most students into an algebra class, but too often that class bears little resemblance to algebra. Critics who would like to support educationally respectable vocational programs protest that we are now committing educational fraud. As educators we should not say that a student is unable to learn a particular subject rather, we should ask what each child can do and how we might help him or her to find an opportunity to do it. Educators should look backward appreciatively at the ideals advanced for the comprehensive high school, and should look forward in plans for living up to those ideals. If possible, one should plan to locate all of our programs (in any geographic area) in one school or on one campus so that students from every program can participate cooperatively in extra-curricular activities and general meetings. In addition, educators should draw on the best of the traditional programs to enrich all of our courses without insisting that they alone constitute intellectual knowledge and should incorporate the highly useful knowledge that inherits in much of what has long been called practical. In doing so, we acknowledge that material addressed to the great existential questions and material centered on the practical must both be addressed in a richer, broader view of education (Noddings, 2015).

\section{Effective Instructional Methods}

The pressure that most of the schools and educators facing recently is to improve student performance in their schools. This is the reason that states are required to administer annual standardized tests in reading and math for all students in grades 3-8. 
The No Child Left Behind Act is a supporter of using the traditional, skills-based programs as a means to achieve student progress goals (Ylimaki, 2007). Schools not able to achieve these goals are subject to corrective action, including conversion to a charter school or staff restructuring and the principals can even lose their jobs. Ylimaki (2007) further elaborates that this kind of pressure is really intense for principals, specially of the schools that have past history of poor achievement.

With the resources becoming accessible and globalization there have been many changes seen in all the different walks of life. One of them is diversity. The immigrants and workers coming from different countries have also made people think how to cater to the diverse population. The biggest challenge is to accommodate diverse students in the same classroom teaching them the same curriculum. Students differ in language, cultural background, educational skills, learning abilities and interests.

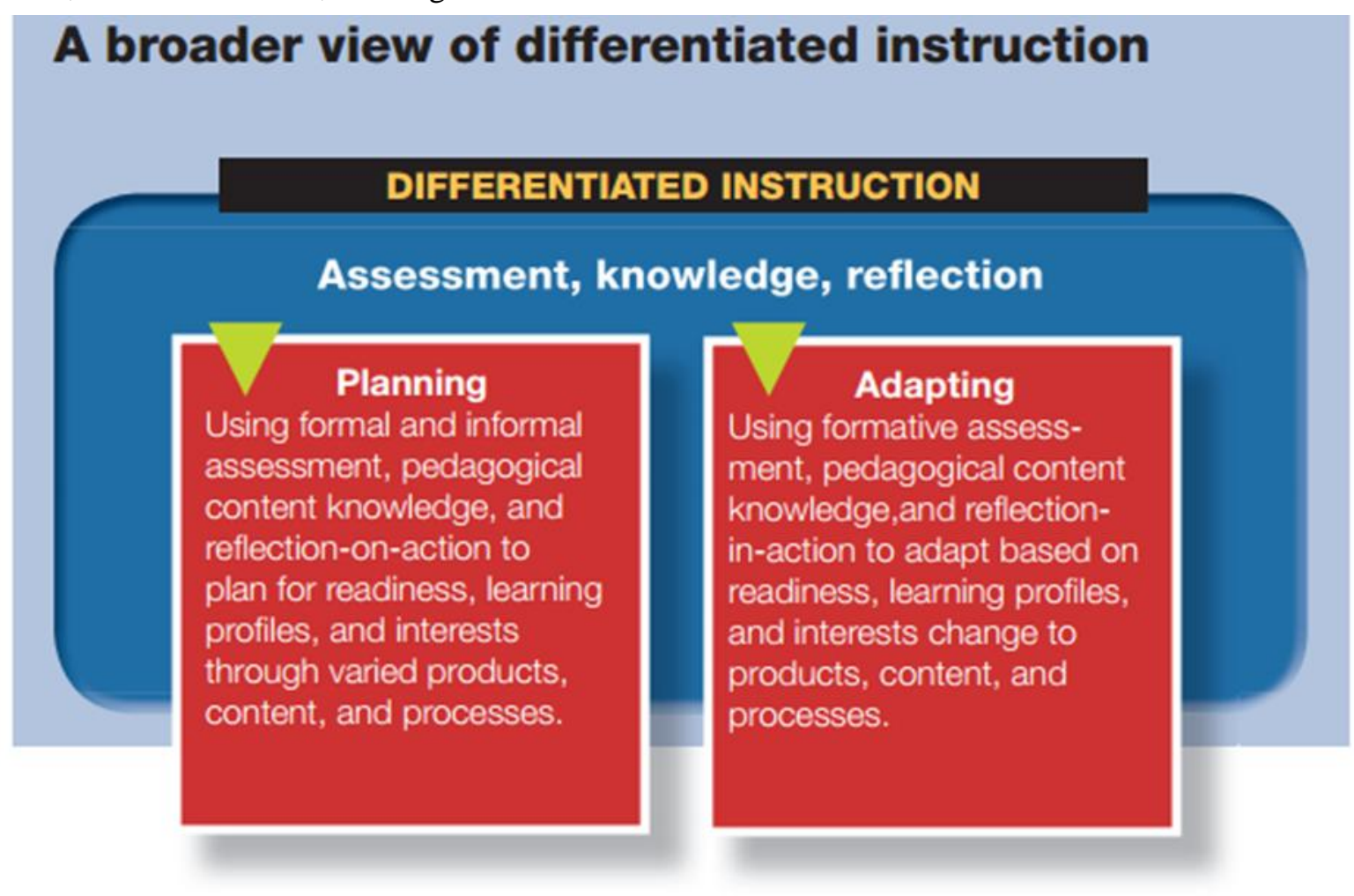

\section{Adaptive teaching as differentiation}

Figure 1.(Parsons, Dodman, \& Cohen 2013).

Therefore, it has become imperative that our instructions in classrooms should be such that best meets students' diverse needs, and teachers must use such measure where they can differentiate their instruction. The researchers are advocating the need for differentiation instruction, as it has shown positive effects on student achievement (Parson, 2012). Differentiation focuses on planning and in the words of Gregory and Chapman (2001) it is "a philosophy that enables teachers to plan strategically in order to reach the needs of the diverse learners in classrooms today".

The teachers play a major role in educating the students, so the teachers when faced with diverse population is required to meet all the aspects of teaching in a way where no none feels left out, and every student's needs are also met. The teacher has to plan the lessons which can be differentiated and will cater to each students' individual needs, interests, and learning profiles (Parsons, Dodman, \& Cohen 2013). The adaptations made by teachers to fit in into their instruction are an important aspect of differentiation. Differentiation instruction refers to this kind of instruction where teacher adopts varied ways to adjust instruction so the requirements of all the students can be met (Parsons, 2012). The effective teachers would not only plan the instruction carefully based on curriculum but can improvise and adapt many new teaching methods to meet the needs of diverse population that were not or could not be anticipated. 
One needs to knowledgeable about their subject and also about the different ways of delivering it to the students. (Parsons, Dodman, \& Cohen 2013). Teachers who are effectively able to adapt to the differentiation in their instruction will be able to assess student progress in multiple ways. These teachers have learnt a lot through their knowledge and experience about delivering the content which makes students learn well.

\section{Curriculum Content and Organization}

The instructional design which the contemporary designers base heir models on grew from the convergence of behavioral psychology, communication theory, and systems engineering. These methods were combined to address the educational requirement to produce improved mass instruction in the 1950s through the 1970s.Early efforts at instructional design focused on designing instructional devices or simulators using self-paced teaching methods that provided guidance and reinforced correct responses (Figueroa, 2014). There is an increase of diverse student population and these differences could be not only ethnic, socioeconomic, and linguistic differences, but also the differences resulting from previous experiences, background knowledge, learning style, needs, or interests. Therefore, it is a big challenge to meet the plethora of learner needs in a course with participants from different backgrounds.

\section{Assessment}

Curriculum, standards and assessment join together to help instructors and curriculum designers to provide the best learning experiences for students. The information that the educators will gather about student's progress helps determine them how to design the classroom, the kinds of experiences, and the content that will help children learn new skills, which will not only help them in class but outside the classroom and in real world practices. Assessments help gather the information one needs for lesson planning and creating stimulating learning environments for children. It helps determine specific goals and objectives, instructors should try to determine what knowledge and/or skills they want their students to learn; what content, skills, and knowledge the activity will assess; and what evidence is needed to appropriately evaluate the selected skills and knowledge (Myers, 2008). The most important aspect of having an assessment done is to make sure that student outcomes are clearly defined and can be measured. Instructors should share goals and objectives with their students so that they know what is expected of them, which keeps them focused on the task. Mayers (2008) suggests that assessments can have a positive impact on the classroom by helping students build on their skills and work on more advanced projects that require a broader knowledge base and skill if the tasks are truly multidisciplinary in nature.

\section{The Roles of Students, Teachers and Institutions}

While designing the curriculum the attention is centered on its development rather than the implementation process. Therefore, it is important that there is a communication between administrators, supervisors, teachers and principals while the curriculum is being implemented. The principal should have open communication lines with all school personnel and promote a strong staff development program to allow teachers the opportunity to successfully incorporate the curriculum change. As principal is the main person of contact, he should encourage the faculty by showing some interest and enthusiasm every now and then. The school administrator is responsible for the success of the implementation process; therefore, his direction is required for the success of curriculum. If a student is involved in curriculum development, it can make him or her take more interest in learning. The students are viewed as disruptive rather than responsible, but on the contrary students can and must modify lesson content according to their own predilections, perceptions, and attitudes (Webb, et al. 1986).Webb, et al(1986) suggests that research has shown that students prefer classroom activities that require their active involvement. Teacher imbibes the good values positivity, learning and shows the students the different way to deal with life situations. They not only learn in classroom but also become the lifelong learners and are open to learn and embrace new opportunities. Therefore, when developing the curriculum, the things that need to be kept in mind are it should be planned in way which makes the students use their brains to learn, explore, evaluate and analyze the learning which comes their way.

\section{Conclusion}

With changing times and the spread of globalization, the diversity is seen in every walk of life. As an instructional designer one needs to keep in mind how to get all the people belonging to different backgrounds get together to learn the skills which will help them not inside the classroom, but beyond it. The students should be taught the skills which are not only theoretical but also practical in real life scenarios. 
When a curriculum is implemented all the stakeholders should have an equal say in it, and everyone's opinion should be considered in developing the content.

\section{References}

Adler, M. J. 1982. The Paideia proposal. New York: Macmillan

Arum, R., \&Roksa, J. 2014. Academically adrift: Limited learning on college campuses. Chicago: University of Chicago Press.

Figueroa, S. (2014). Instructional designers' perceptions of their personal background and experiences in their work.OAlster.

Gregory, G.H. \& Chapman, C. (2001). Differentiated instructional strategies: One size does not fit all. Thousand Oaks, CA: Corwin.

Myers, S. (2008). Performance-based assessment. Research Starters Education (Online Edition),

Noddings, N. (2015). A richer, broader view of education. Society, 52(3), 232-236. doi:10.1007/s12115-015$9892-4$

Parsons, S.A. (2012). Adaptive teaching in literacy instruction: Case studies of two teachers. Journal of Literacy Research, 44, 149-170.

Parsons, S. A., Dodman, S. L., \& Cohen Burrowbridge, S. (2013). Broadening the view of differentiated instruction. Phi Delta Kappan, 95(1), 38.

Webb, C. \&et.al (1986). Student involvement in curriculum development: A different view. Retrieved from http://eric.ed.gov/?id=ED241406.

Ylimaki, R. M. (2007). Instructional leadership in challenging US Schools. International studies in educational administration (Commonwealth Council for Educational Administration \& Management (CCEAM)), 35(3), 11-19. 